\title{
A PRESENÇA DO DISCURSO DIDÁTICO NO TEXTO JORNALÍSTICO DO PORTAL G1
}

\author{
(The presence of didatic discourse in journalistic text at Portal G1)
}

\author{
Ana Paula RABELO ${ }^{1}$ \\ Universidade Federal do Ceará \\ Izabel MAGALHÃES ${ }^{2}$ \\ Universidade de Brasília
}

Tiago Martins da CUNHA ${ }^{3}$

Universidade da Integração Internacional da Lusofonia Afro-Brasileira

\section{RESUMO}

A presente pesquisa teve como objetivo identificar como ocorre a recontextualização (MAGALHÃES, 2015) a partir da relação entre discurso informativo e discurso didático em 29 matérias (de 2014 a 2017) publicadas no Portal G1(Lava Jato). Além deste, também foi nosso objetivo identificar como o didatismo recorre ao uso da repetição dos argumentos indutivos: exemplo e ilustração (PERELMAN; OLBRECHTSTYTECA, 1996; FIORIN, 2017). Para tanto, utilizamos a Análise de Discurso Crítica (ADC) como teoria e método. Como teoria, quando nos reportamos às noç̃̃es de discurso (FAIRCLOUGH 2001 [1992]; FAIRCLOUGH, 2003) e recontextualização (MAGALHÃES, 2015); e como método, quando nos apoiamos no enquadre metodológico sugerido por Chouliaraki e Fairclough (1999). No procedimento metodológico, associamos a ADC à Linguística Computacional para ilustrar a ocorrência de termos associados ao discurso didático (CHARAUDEAU, 2009) nas matérias analisadas, bem como para analisar a recontextualização por meio da repetição de termos. Identificamos uso excessivo de didatismos tanto nos aspectos estruturais, quanto na linha argumentativa, ao ponto de recontextualizar as narrativas de modo a tornar nebulosa a relação entre os fatos narrados pela mídia e os eventos ali descritos.

Palavras-chave: Análise de Discurso Crítica. Portal G1. Recontextualização. Discurso Didático. Lava Jato.

\begin{abstract}
The present research had the aim of investigating how recontextualization (MAGALHÃES, 2015) occurs in the relation between an informative discourse and a didactic discourse, in 29 stories (from 2014 to 2017) published in Portal G1 (Lava Jato/Car Wash). In addition to this, it was our aim to identify how didacticism uses the repetition of inductive arguments: example and illustration (PERELMAN; OLBRECHTS-TYTECA, 1996; FIORIN, 2017). For this, we use Critical Discourse Analysis (CDA) as a theory and method. As a theory, when we refer to the notions of discourse (FAIRCLOUGH 2001 [1992]; FAIRCLOUGH, 2003), and recontextualization (MAGALHÃES, 2015); and as a method, when we rely on the methodological framework suggested by Chouliaraki and Fairclough (1999). In the methodological procedure, we associate CDA with

${ }^{1}$ Doutora pelo Programa de Pós-Graduação em Linguística da UFC - PPGL/UFC. Docente do curso de Letras - Língua Portuguesa, da Universidade da Integração Internacional da Lusofonia Afro-Brasileira - Unilab. Integrante do Grupo de Estudos Críticos em Discurso e Sociedade (Atmos/Unilab) e da Rediscurso, Rede de Grupos de Discurso e Pesquisas em Discurso e Sociedade - Ceará. Pesquisadora Pibic/CNPq. (anarabelo.p@unilab.edu.br).

${ }^{2}$ Doutora em Linguística (1985), com bolsa do CNPq, e Pós-Doutora (1993 a 1994), com bolsa da Capes, Universidade de Lancaster - Reino Unido. Professora aposentada da Universidade de Brasília e Professora Visitante na Universidade Federal de Goiás. Membro efetivo da Associação Latino-Americana de Analistas do Discurso (Aled), da Associação Brasileira de Linguística (Abralin) e da Associação de Linguística Aplicada do Brasil (Alab). Pesquisadora 1 do Conselho Nacional de Desenvolvimento Científico e Tecnológico (CNPq). (mizabel@uol.com.br)

${ }^{3}$ Doutor pelo Programa de Pós-Graduação em Linguística da UFC - PPGL/UFC. Docente da Universidade da Integração Internacional da Lusofonia Afro-Brasileira - Unilab, no setor de Língua Inglesa, com experiência na área de Linguística, ênfase em Tradução e Terminologia aplicadas à Língua Estrangeira, assim como na área de Linguística Computacional e no desenvolvimento de Tradutores Automáticos. (tiagotmc@unilab.edu.br)
\end{abstract}


Computational Linguistics to illustrate the occurrence of terms associated with the didactic discourse (CHARAUDEAU, 2003) in the analyzed stories; we also examine recontextualization in the repetition of terms. We identify excessive use of didactism in both the structural and argumentative aspects, to the point of recontextualizing the didactic discourse in order to blur the relationship between the facts narrated by the media and the events described there.

Keywords: Critical Discourse Analysis. Portal G1. Recontextualization. Didactic Discourse. Car Wash.

Recebido em: agosto 2018

Aceito em: março 2019

DOI: $10.26512 /$ les.v20i1.11079

\section{INTRODUÇÃ̃o}

Entre 1964 - 1985, período de ditadura no Brasil, o jornalismo conseguiu uma voz de resistência longe da imprensa hegemônica. Para Siebra (2006), o papel da "imprensa nanica" foi de grande relevância para a apresentação de outros pontos de vista. Para manter "aceso" o debate político, o contraponto era apresentado por pequenos jornais como Pif-paf, Opinião, Movimento, Em Tempo, Versus, Bondinho, O Sol e O Pasquim. Nos anos 2000, com a consolidação das redes sociais, surgiu uma fissura para a democratização da mídia e, consequentemente, a abertura para o amplo debate político sobre questões sociais que são caras às maiorias sociais brasileiras.

É nesse contexto de abertura para a pluralidade de formas de distribuição de informações (rádio, tv, impresso e web) - mas não de real democratização da mídia -, que reconhecemos que o papel da mídia hegemônica nas transformações sociais tem se revelado mais significativo, dada a ampla capacidade de produção e distribuição de dados nos mais remotos espaços (FAIRCLOUGH, 2001 [1992]). Não nos referimos apenas ao volume de informação produzida ou distribuída em sites, portais e blogs, mas à capacidade de fazer chegar a informação nos mais distantes e ermos lugares.

Para Ramonet (2013), os meios de comunicação foram pensados como instrumentos de democratização da informação, mas se apresentam pouco úteis à cidadania por estarem "a serviço" de seletos grupos políticos. Ora, se grupos podem exercer poder sobre outros e estes, por sua vez, podem aceitá-lo ou recusá-lo (VAN DIJK, 2012), e se esses grupos seletos (donos da mídia brasileira) concentram uma grande capacidade de produção e distribuição de informação, entendemos que a relação entre mídia e história, experienciada pela sociedade brasileira na construção do Golpe parlamentar, jurídico e midiático de 2016 (que, em certa medida, dialoga com a narrativização das tramas políticas da "Operação Lava Jato" elaborada pelo portal G1) também depende do aceite ou da recusa de seus leitores. Assim, estamos investigando condições específicas de construção discursiva para que esse discurso possa ter uma reação de acolhimento (DE 
ACEITAÇÃO) mais propícia, possibilitando também o envolvimento dos leitores e leitoras na divulgação das narrativas, que assumem o papel de "conarradores(as)".

Por que a imprensa usaria o discurso didático? A escolha pelo uso do didatismo (apesar do risco de vulgarização) pode criar a legitimidade do discurso das mídias, podendo desqualificar qualquer outro discurso que possa ser construído em outras esferas discursivas, inclusive na esfera jurídica. Assim, o/a cidadão/ã leigo/a, sem acesso à linguagem jurídica, opta pela coleta de informações claras e acessíveis disponibilizadas em abundância nos jornais impressos, nas rádios, nas tvs e nas revistas.

Para Charaudeau (2009), um dos aspectos que valida o discurso informativo é o fato de ser o "fornecedor de informação", ou seja, ser a fonte. A fonte só encontra o respeito do público quando dois fatores são utilizados de modo apropriado: quantidade e qualidade. Ciente de não ser possível acompanhar todo o processo de investigação em todas as veredas percorridas nas 50 fases da “Operação" (até abril de 2018); e, ao mesmo tempo, ciente de que terá mais validade quanto mais abrangência conseguir (alcance de difusão, número de publicação, detalhamento de informações), a instância midiática vê-se obrigada a "dotar-se de meios que lhe permitam abranger o máximo de acontecimentos, selecioná-los e verificá-los” (p. 74 - 75). Entendemos que o discurso didático cumpre a função de amparar o discurso informativo, criando uma linha de raciocínio por meio do didatismo na organização estrutural do texto e no texto escrito, ao mesmo tempo em que as matérias de cunho didático ampliam a produção do que dizer (com novos conteúdos) e do como dizer (com recontextualização).

Um problema decorrente do uso do discurso didático é a vulgarização da informação (CHARAUDEAU, 2009). Para Charaudeau (2009, p. 62 - 63),

A vulgarização, nas mídias, não se limita a procurar "explicar com simplicidade", como se diz nas escolas de jornalismo [...] Quanto mais uma informação for precisa e detalhada, inscrevendo-se numa reflexão sistêmica pela ação de um especialista, menos ela será comunicável fora do campo de inteligibilidade que a produziu. Mas, além disso, como a vulgarização midiática é constantemente atravessada por uma visada de captação, isso tende a transformá-la numa vulgarização dramatizada. Desse ponto de vista, pode-se dizer que as mídias trapaceiam cada vez que uma explicação é apresentada como decodificação simplificada de uma verdade oculta, como acessível a todos [...].

Reconhecemos que o uso do didatismo pode configurar-se como uma ameaça à construção de um texto comprometido com a descrição dos fatos, uma vez que cada recontextualização (MAGALHÃES, 2015, p. 177) implica que "Essas diferentes interpretações e representações materializam-se em diferentes escolhas linguísticas ". Para onde caminham essas representações? 
Quais interesses ideológicos sustentam as que ganham eco na mídia hegemônica? Novos e mais amplos estudos precisam ser realizados.

Reconhecemos, também, que a repetição das mesmas ideias apresentadas em diferentes formas de acesso de um mesmo site pode confundir o/a leitor/a, criando uma impressão de um volume maior de fatos do que o que realmente existe. Além disso, acreditamos que a repetição de um mesmo tema possibilita recontextualizações distintas, mas a cada novo texto, com diferentes graus de informatividade, com fragmentos de informações novas, que possam "ativar o gatilho" para esse tema/subtema, que será melhor detalhado em outro texto, possivelmente mais longo e didático, para sensibilizar o público-alvo e envolvê-lo na defesa da tese defendida.

Dessa forma, a presente pesquisa teve como objetivo identificar como ocorre a recontextualização (MAGALHÃES, 2015) na relação entre discurso informativo e discurso didático, em 29 matérias (de 2014 a 2017) publicadas no Portal G1/Lava Jato. Além deste, também foi nosso objetivo identificar como o didatismo recorre ao uso da repetição de argumentações fundamentadas na estrutura do real, argumentos indutivos: exemplo e ilustração (PERELMAN; OLBRECHTS-TYTECA, 1996; FIORIN, 2017).

\section{Metodologia}

Este trabalho é resultado de um diálogo entre teóricos que trabalham com discurso e sociedade, mas que prioriza a Análise de Discurso Crítica como teoria e método. Como teoria, quando nos reportamos às noções de discurso (FAIRCLOUGH, 2001 [1992]; CHOULIARAKI e FAIRCLOUGH, 1999; FAIRCLOUGH, 2003) e recontextualização (MAGALHÃES, 2015). Como método, quando seguimos a proposta de enquadre metodológico elaborado por Chouliaraki e Fairclough, 1999. Para esses autores, o enquadre requer a identificação de um problema, aqui descrito como o uso do discurso didático na recontextualização dos dados da "Operação Lava Jato" pelo Portal G1.

No procedimento metodológico, buscamos, no primeiro momento, observar a presença do didatismo na estrutura da notícia (infográficos, narrativas com indicadores de tempo ou de lugar, segmentação textual explícita ou implícita, imagens) e no texto (exemplos, ilustrações textuais, uso do verbo 'entender'). Também associamos a ADC à Linguística Computacional para ilustrar a ocorrência de termos ligados ao discurso didático (CHARAUDEAU, 2009) nas 29 matérias analisadas.

Identificado o problema, estabelecemos como estratégias de análise para os obstáculos a serem superados (segunda etapa do enquadre metodológico) a análise de conjuntura realizada nas 
seções que descrevem a crise da democracia brasileira e a relação da mídia com a crise política. Ao discutir o problema na prática em que se situa, apresentamos propostas de futuros trabalhos acadêmicos que possam aprofundar os estudos sobre a mídia brasileira, em especial o Portal G1/Política, mas não sugerimos proposta para superar os obstáculos, uma vez que o acompanhamento da Lava Jato pelo portal G1 ainda está em curso, ultrapassando a quadragésima quarta operação.

Acompanhamos o portal nos anos de 2016 e 2017, de modo assistemático, fazendo buscas de matérias também sobre “Operação Lava Jato", já publicadas nos anos de 2014 e 2015. O portal, no ano de 2016 (Imagem 1), apresentava duas vias de acesso a esse tema: uma no "Menu" principal e outra na página "Lula sob investigação", mas ainda era possível acessar outras matérias, em outros espaços, sobre o mesmo tema no portal.

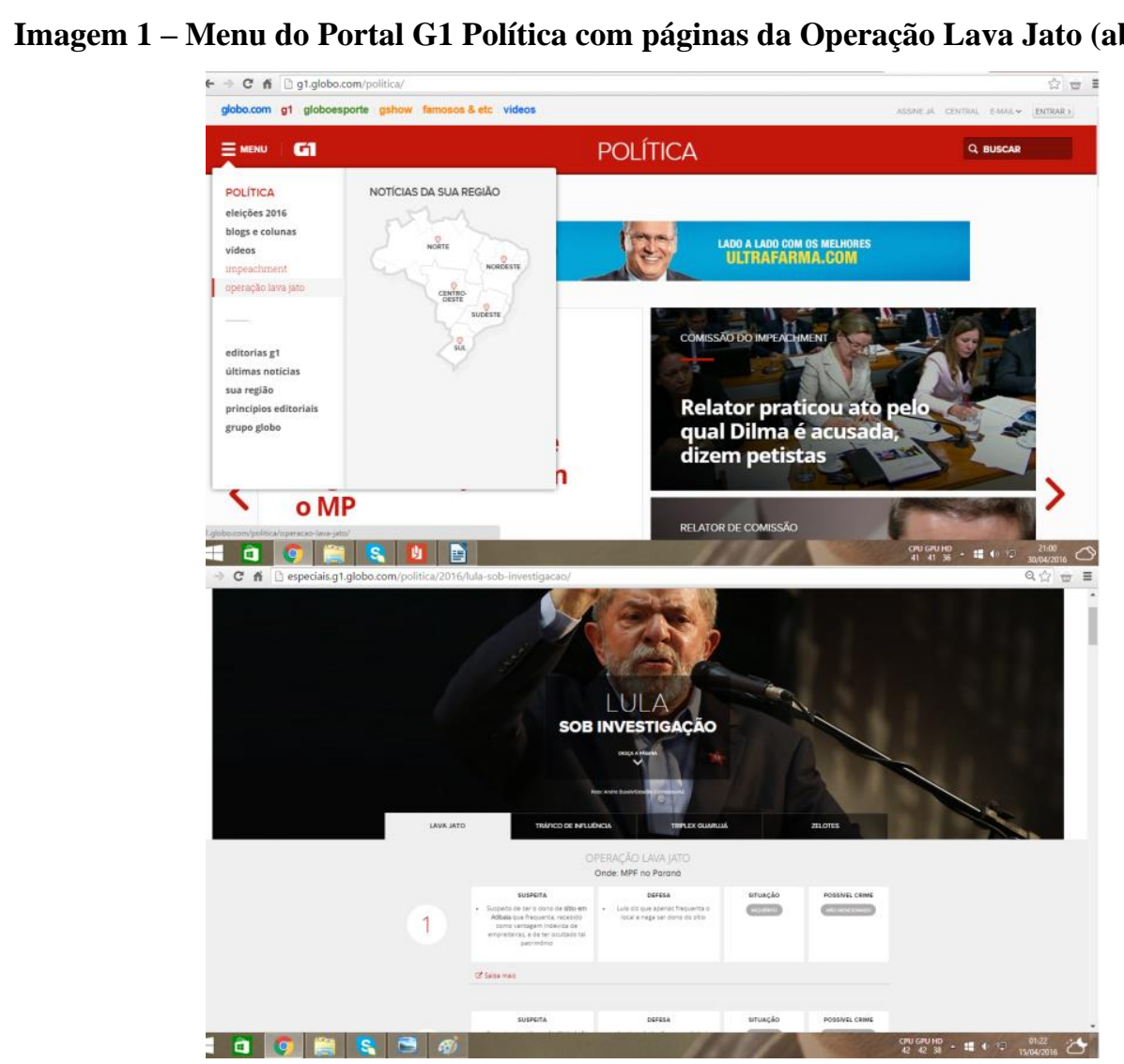

Fonte: Portal G1 (acesso em abril de 2016)

Apesar de o discurso informativo ser proeminente nos gêneros jornalísticos, verificamos a recorrência do discurso didático e da repetição em textos jornalísticos divulgados pelo Portal G1, no que se refere ao tema "Operação Lava-Jato". 
Compreendemos que, nesta análise, o discurso midiático, associado ao discurso didático (CHARAUDEAU, 2009), fez uso de duas categorias da retórica (argumentações fundamentadas na estrutura do real - argumentos indutivos): exemplo e ilustração (PERELMAN, OLBRECHTSTYTECA, 1996; FIORIN, 2017). Entendemos que o detalhamento (às vezes, excessivo) das informações é uma estratégia discursiva para criar um vínculo com o/a leitor/a ao ponto de ele sentir-se confiante para desenvolver (com criatividade) o tema. Essa capacidade criativa pode, contudo, ficar comprometida quando dados relevantes são negados, ou apresentados em contextos desfavoráveis à sua saliência.

\section{Resultados}

O ponto central de nossa argumentação é que a mídia, instrumento do capital financeiro brasileiro e internacional, cria estratégias muito didáticas para ensinar à população com baixo grau de escolaridade e de criticidade (cf. dados sobre qualidade da leitura do brasileiro/a) conceitos que podem ser pertinentes para ela em dados momentos políticos, como o conceito de "corrupção".

Charaudeau (2009, p. 77) compreende que, assim como um/a historiador/a, um/a jornalista

[...] não pode visar um discurso perfeitamente didático (mesmo que determinada intenção pedagógica o atravesse e que se possa encontrar grande quantidade de traços didáticos em seu discurso), pois as exigências de organização do saber no discurso didático, sua construção que prevê provas de verificação (exercícios de aplicação), e de avaliação, enfim, a austeridade de sua apresentação, são, de fato, incomparáveis com uma informação que deve captar o público em geral. Se todo discurso didático é parte de uma atividade discursiva mais global de vulgarização, esta, no entanto, não é necessariamente didática, a menos que se especifique o que é didaticamente e que se conclua pela existência de uma didaticidade midiática diferente da escolar, universitária, administrativa, etc.

Para esse autor, o/a jornalista/a, no que diz respeito às contradições do seu contrato de informação com o público alvo, deveria posicionar-se como um/a mediador/a, alguém que valorizasse a possibilidade de "fornecer informação". O/a jornalista cumpre o papel de "revelador da informação oculta e, nesse sentido, assume o papel de adversário dos poderes instituídos e de aliado do público [grifo nosso], procedendo a interrogatórios, instruindo questões, aspirando papéis de juiz ou detetive [grifo nosso]" (CHARAUDEAU, 2009, p. 78). Se ele/a fornecesse apenas a informação, poderia disponibilizar as pistas necessárias para que a justiça exercesse o seu papel. Mas as suas recontextualizações (MAGALHÃES, 2015), fundadas em informações incompletas, podem soar como tendenciosas, e podem comprometer o julgamento da população. No caso da "Operação Lava Jato”, a mídia hegemônica tornou-se aliada do público. 
Muitos estudiosos/as e pesquisadores/as reconhecem a força que a imprensa hegemônica tradicional (mesmo os sites) teve durante o Golpe de 2016 no Brasil. A derrubada de poder não é um fato isolado. Outros países também estão passando por processos similares ao vivenciado pelo Estado Brasileiro. Para Paz Pérez Esquivel (2016, s/p):

Não há casualidades em tudo o que está acontecendo agora contra o governo de
Dilma. Isso faz parte de um projeto de recolonização continental. Já houve
experiências piloto no continente que devem ser lembradas. A metodologia é a
mesma. O que aconteceu em Honduras, com a derrubada de Manuel Zelaya, e
depois no Paraguai, contra o governo de Fernando Lugo, foram ensaios de golpes
de Estado de um novo tipo. Golpes de Estado que não precisam dos Exércitos.
Basta ter os meios de comunicação, alguns juízes e dirigentes políticos da oposição
para provocar a desestabilização de um governo.

As construções das narrativas precisam ser minuciosamente estudadas para que sejam identificadas as diferentes estratégias discursivas utilizadas em cada uma das 50 fases da "Operação Lava Jato" (até abril de 2018) e como essas estratégias obtiveram o efeito de engajamento junto à audiência, uma vez que as pessoas passaram a repudiar o tema política, ao mesmo tempo em que acompanhavam as matérias da Lava Jato como uma trama novelesca, separando os personagens em protagonistas e antagonistas. Mais, aprendendo os nomes mais importantes, por exemplo, entre os 72 delatores descritos em lista na página oficial do Portal G1.

Elencamos 10 matérias publicadas pelo Grupo Globo de Comunicação, organizadas de março de 2014 a junho de 2017, que apresentam didatismo já no título e/ou são detalhistas na apresentação dos dados com presença de "exemplos" e "ilustrações" (PERELMAN, OLBRECHTSTYTECA, 1996; FIORIN, 2017).

Quadro 1 - Descrição das matérias com discurso didático, publicadas entre 2014 e 2017

\section{Titulo da Matéria}

1 Tire

2

Cade aprova venda de fatia de companhia de gás da Petrobras [Cade aprovou sem restrições a venda de 49\% da subsidiária de gás da Petrobras]

3 Empresas investigadas têm contratos bilionários com a 4/11/2014 Petrobras

$4 \quad$ Entenda a operação Lava Jato (vídeo)

5 Entenda as fases das investigações da operação Lava 28/06/2015 Jato (vídeo)

\section{Data/hora de publicação \\ fonte}

$23 / 06 / 2017$ atualizado em $12 / 04 / 2018$

$02 / 12 / 2015$ atualizado em 02/12/2015

$29 / 08 / 2015$ $13 / 06 / 2015$ $14 / 04 / 2014$

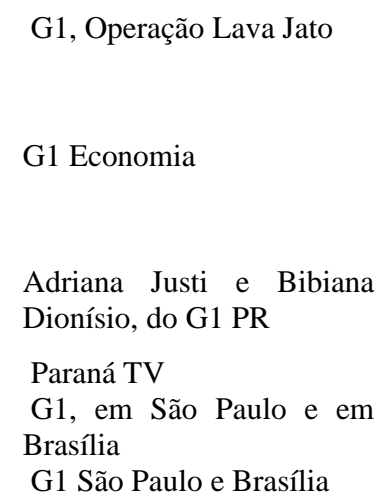

G1, Operação Lava Jato

G1 Economia

Adriana Justi e Bibiana Dionísio, do G1 PR

Paraná TV

G1, em São Paulo e em

Brasília

G1 São Paulo e Brasília

Jornal Nacional, postado no G1/Política 


\begin{tabular}{|c|c|c|c|}
\hline 6 & Entenda a 11 fase da operação Lava Jato (vídeo) & $10 / 04 / 2015$ & G1 \\
\hline 7 & $\begin{array}{l}\text { Animação: Entenda a Operação Lava Jato em três } \\
\text { passos (vídeo - animação) }\end{array}$ & 28/01/2015 & G1 \\
\hline 8 & $\begin{array}{l}\text { Após decisão do STF, ex-diretor da Petrobrás sai da } \\
\text { prisão em Curitiba (retoma trechos da matéria } 10 \text {, de } \\
25 / 04 / 2014 \text { ) }\end{array}$ & $19 / 05 / 2014$ & G1 PR \\
\hline 9 & $\begin{array}{l}\text { Entenda os processos já abertos contra os réus da } \\
\text { operação Lava Jato }\end{array}$ & $\begin{array}{l}25 / 04 / 2014 \\
\text { Atual. } \\
28 / 01 / 2015\end{array}$ & $\begin{array}{l}\text { Samuel Nunes e Fernando } \\
\text { Castro (G1 Paraná RPC) }\end{array}$ \\
\hline 10 & $\frac{\text { Entenda a compra da refinaria de Pasadena pela }}{\text { Petrobrás }}$ & $20 / 03 / 2014$ & G1 SP \\
\hline
\end{tabular}

A primeira matéria da lista, "Tire suas dúvidas: Perguntas e respostas sobre a Lava Jato", é composta por uma página com um conjunto de questionamentos mais frequentes, como apresentamos a seguir:

\section{Imagem 2 - Exemplos de perguntas e respostas do Portal G1}
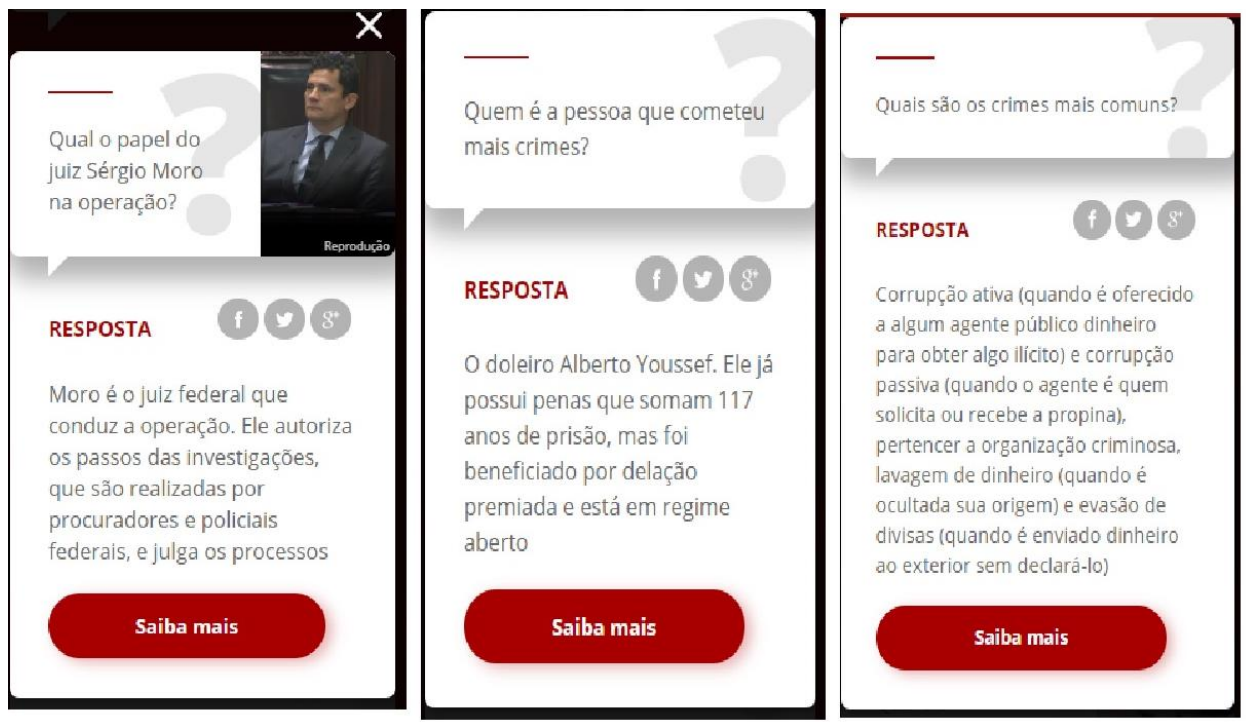

Fonte: Portal G1 (acesso em abril de 2016)

As perguntas ficam disponíveis na página dentro de "balões" de diálogo, como os utilizados em revistas em quadrinho. Ao acessar o link pelo qual se tem interesse, surge uma aba com uma resposta objetiva, oferecendo um novo link intitulado "Saiba mais", onde é possível obter o detalhamento do tema, com vídeos, fases, trajetória histórica do caso e/ou infográficos.

Esse discurso didático recontextualiza a "Operação Lava Jato", que teria, segundo site oficial do Ministério Público Federal (MPF), iniciado com investigação da Justiça Federal de Curitiba, em março de 2014, quando "foram investigadas e processadas quatro organizações criminosas lideradas por doleiros, que são operadores do mercado paralelo de câmbio" (BRASIL/MPF). Somente depois, o MPF teria recolhido as provas do que denominou "um imenso esquema criminoso de corrupção envolvendo a Petrobras" (BRASIL/MPF). Sob a responsabilidade do Ministério, o procurador-geral da República, Rodrigo Janot, designou a primeira comissão, em 
abril de 2014. A operação conta com ação de três instituições: MPF no Paraná, Procuradoria Geral da República (PGR) e Tribunal Superior de Justiça (TSJ), além da ação direta da Polícia Federal $(\mathrm{PF})$.

Na construção discursiva da mídia, o governo da então Presidente Dilma Rousseff começa a ficar fragilizado, dada a associação do seu nome aos casos de corrupção da Petrobrás. Diferentes matérias, mesmo que não seja ela o tema principal, fazem a escolha do uso e da repetição de seu nome e/ou do nome "corrupção". Tendo como base a Linguística Computacional, avaliamos a ocorrência das palavras: "corrupção", "tráfico de influência", "quadrilha", "Lula” e "Dilma”. As maiores ocorrências, de março a dezembro de 2014, são os termos "corrupção" e "Dilma".

\section{Gráfico 1 - Número de ocorrências dos termos corrupção, Lula e Dilma, em 2014, no portal G1 (matérias selecionadas para análise). ${ }^{4}$}

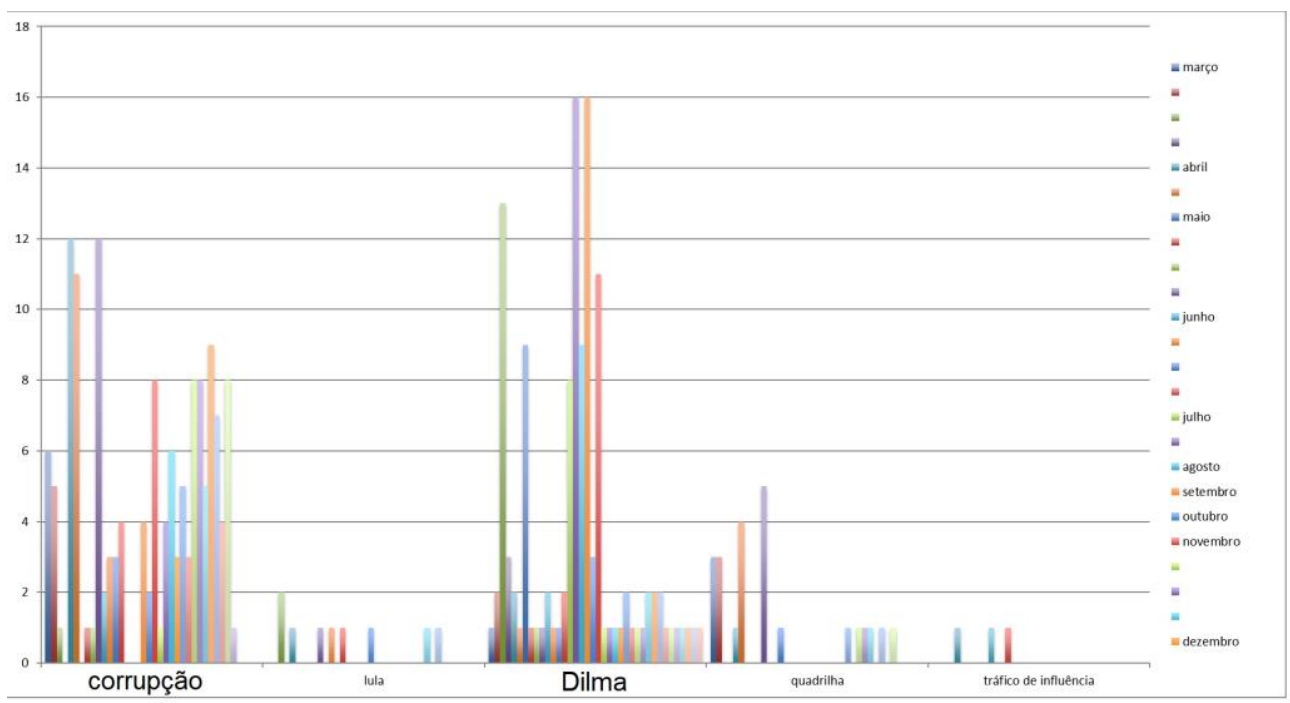

Fonte: Elaboração nossa

Mesmo quando há baixa ocorrência, ainda assim, é construído um cenário negativo para a presidente que tem o seu nome recorrentemente citado em notícias de um dos maiores jornais do Brasil, numa página especial de política responsável pelo jornalismo investigativo de um relevante escândalo de corrupção da história do país: a "Operação Lava Jato".

Ainda com o apoio da Linguística Computacional, buscamos relacionar a frequência de uso dos termos "entenda", "infográfico" e "etapas". O termo infográfico não foi detectado em muitas das reportagens e notícias que já havíamos descrito como utilizadoras desse recurso didático. Identificamos que o termo "infográfico" ou estava preso à imagem do próprio infográfico e não era

\footnotetext{
${ }^{4}$ Nomes buscados na pesquisa: "corrupção", "Lula", "Dilma", "quadrilha" e "tráfico de influência"; considerando os meses de março a dezembro de 2014.
} 
detectado pelo programa, ou havia omissão do termo. Optamos, então, por avaliar a frequência de uso da palavra "entenda", fazendo a busca por "entend-". Detectamos 419 ocorrências.

Avaliamos que as páginas com estruturas mais complexas são as das matérias "Tire suas dúvidas: Perguntas e respostas sobre a Lava Jato", "Entenda a operação Lava Jato", "Entenda a compra da refinaria de Pasadena pela Petrobrás", "Entenda os processos já abertos contra os réus da operação Lava Jato", de 25/abril/2014 e "Conexões da Lava Jato", um infográfico, de 17/11/2015, associado à matéria de 25 de abril, que apresenta um detalhamento das conexões no processo Lava Jato, com base na leitura da mídia.

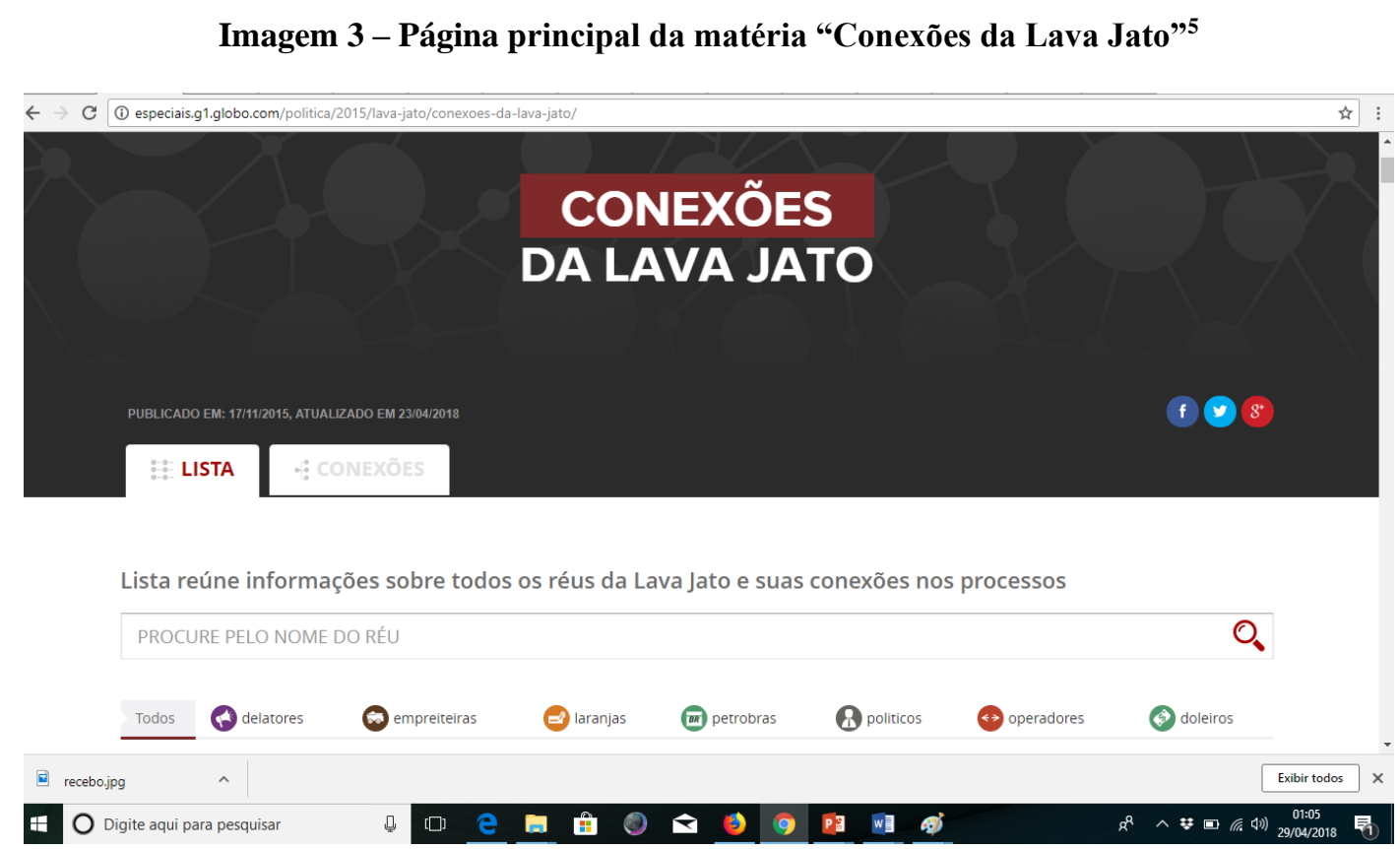

Fonte: http://especiais.g1.globo.com/politica/2015/lava-jato/conexoes-da-lava-jato/

No espaço reservado à pesquisa na página "Conexões", há a sugestão de texto: "PROCURE PELO NOME DO RÉU”, escrito todo em letras maiúsculas. São especificadas as categorias de quem pode ser réu: "delatores", “empreiteiras", "laranjas", "Petrobrás”, "políticos", “operadores” e “doleiros”. Na página de "delatores” estavam listados, no dia 29 de abril de 2018, 72 nomes organizados em 15 linhas e 4 colunas. Cada um dos nomes aparece em uma caixa com foto. Ao clicar no link, uma nova página abre, apresentando a descrição dos "crimes de denúncia", as "denúncias", a "defesa" e as "conexões" baseadas nas denúncias. Associado ao nome do delator, estão todos os nomes a ele conectados com, quase sempre, apresentação de fotos. No item

\footnotetext{
${ }^{5}$ Uma lista reúne informações sobre todos os réus da Lava Jato e suas conexões nos processos /Procure pelo nome do réu/todos/delatores/empreiteiras/laranjas/Petrobrás/políticos/operadores/doleiros.
} 
“empreiteiras", há 101 nomes listados, e no item "Laranja" estão 76 nomes, em "Petrobrás" 20 (caracterizados como funcionários da Petrobrás e familiares), 71 "políticos" e familiares, 102 “operadores" e 38 "doleiros" e relacionados. Assim como a página "Entenda a operação Lava Jato", com trajetória cronológica, infográficos e exemplos, a página "Conexões da Lava Jato" apresenta uma complexidade visual e um detalhamento das informações que, mesmo que não sejam ainda comprovadas (na experiência jornalística de escrever antes de verificar os fatos), passam a impressão de verdade, recontextualizando para a criação de um cenário perfeito para "um dos piores crimes da história do Brasil", quando sabemos que o caso Banestado é mais complexo que a novelesca trama muito bem narrada pelo Portal G1.

Além dessa organização visual descrita anteriormente, o portal ainda dispõe de um volume de matérias fragmentadas que não permitem que o leitor compreenda a relação entre os fatos, como acontece com a posição favorável para a soltura do ex-diretor da Petrobrás, Paulo Roberto Costa.

\section{Quadro 2 - Descrição das matérias publicadas no Portal G1, entre 19/05/2014 e 20/05/2014, sobre a posição do} Supremo Tribunal Federal (STF) em relação à Lava Jato

\begin{tabular}{|c|c|c|}
\hline Data & Título & Responsável \\
\hline $\begin{array}{l}\text { 19/05/2014 } \\
12 \mathrm{~h} 34 \\
\text { Atual 19/05/2014 }\end{array}$ & $\begin{array}{l}\text { Ministro manda soltar presos da Lava Jato e } \\
\text { ordena que ação vá para o STF } \\
\text { Presos devem entregar passaportes e ficar na região em que } \\
\text { residem. Para Teori Zavascki, Justiça do PR deveria ter } \\
\text { enviado processo ao STF. }\end{array}$ & $\begin{array}{l}\text { Camila Bomfim e Mariana } \\
\text { Oliveira }\end{array}$ \\
\hline $\begin{array}{l}19 / 05 / 2014 \\
16 h 39\end{array}$ & $\begin{array}{l}\text { Após decisão do STF, ex-diretor da Petrobrás sai } \\
\text { da prisão em Curitiba. } \\
\text { Decisão é do ministro Teori Zavascki, do Supremo Tribunal } \\
\text { Federal. Paulo Roberto Costa deve entregar o passaporte às } \\
\text { autoridades. }\end{array}$ & G1 PR \\
\hline $\begin{array}{l}\text { 19/05/2014 } \\
19 h 51\end{array}$ & $\begin{array}{l}\text { Juiz diz ao STF que há risco de fuga se presos da } \\
\text { Lava Jato forem soltos } \\
\text { Ministro Teori Zavascki suspendeu ações penais e mandados } \\
\text { de prisão. } \\
\text { Juiz [Moro] soltou ex-diretor da Petrobras e perguntou se } \\
\text { isso vale para outros } 11 \text {. }\end{array}$ & G1 Brasília \\
\hline $\begin{array}{l}20 / 05 / 2014 \mathrm{~b} \\
11 \mathrm{~h}\end{array}$ & $\begin{array}{l}\text { Ministro do STF revê decisão e mantém } 12 \\
\text { prisões da Lava Jato } \\
\text { Ex-diretor da Petrobras foi solto por ordem do Supremo na } \\
\text { segunda (19). } \\
\text { Teori Zavascki analisará processo antes de decidir sobre } \\
\text { novas solturas. }\end{array}$ & $\begin{array}{l}\text { Camila Bomfim e Mariana } \\
\text { Oliveira }\end{array}$ \\
\hline
\end{tabular}

No quadro 2, a decisão inicial de suspender os mandatos de prisão, do Ministro do STF Teori Zavaski, justifica-se "por entender que pode ter havido 'ilegalidade' nos atos de Moro" (BOMFIM; OLIVEIRA, 2014a, s/p), uma vez que, havendo indícios de envolvimento de deputados federais, o caso deveria ter sido reportado ao STF. Após o pedido de suspensão dos mandados de prisão, o Juiz do Paraná que é responsável pela "Operação Lava Jato", Sérgio Moro, questionou o STF no seguinte texto oficial, publicado na reportagem de Bomfim e Oliveira (2014a, s/p): “A fim 
de evitar erros de interpretação da referida decisão, oficie-se, com urgência e por fax, ao gabinete do ministro Teori Zavascki solicitando, com urgência, esclarecimentos do alcance da aludida decisão [grifo nosso]". É o juiz do Paraná que convence o Ministro do STF a mudar e rever sua decisão sobre a possibilidade de soltura dos presos, sob o argumento da possibilidade de fuga.

Trecho 1 [texto de BOMFIM; OLIVEIRA, 2014b, s/p] A decisão de Zavascki [de manter presas 12 pessoas envolvidas na Operação Lava Jato] foi tomada após o juiz federal do Paraná Sérgio Moro [grifos nossos] advertir que havia risco de fuga para o exterior. Na segunda-feira (19), ao analisar um pedido de Paulo Roberto Costa, um dos 13 presos na operação da PF, o magistrado da corte superior determinou a suspensão de todas as ações penais e dos inquéritos relacionados ao caso, além de ordenar a remessa dos processos ao Supremo.

A referência ao ministro do STF pelo nome [Zavascki], sem nenhuma indicação de cargo, na mesma sentença em que um juiz federal de um estado tem a identificação do cargo e a apresentação do nome completo pode colaborar para uma construção assimétrica de poder que não equivale à realidade: de que um juiz federal de um estado tem mais decisão de poder que um Ministro do STF. A recontextualização orienta o/a leitor/a a crer que a revisão da tomada de decisão do STF só ocorreu em decorrência da posição enérgica - "solicitando, com urgência, esclarecimentos do alcance da aludida decisão" - do juiz Sérgio Moro.

Diante dessa relação de poder, não podemos desconsiderar - como afirmam van Dijk (2012) e Fairclough (2001 [1992]) - que aqueles que têm mais poder também têm as melhores condições de produção e distribuição da informação. Também são eles que têm possibilidades de desempenhar diferentes papéis, produzir diferentes gêneros, em situações comunicativas variadas. “[...] Eles controlam os diálogos formais com os subordinados, presidem reuniões, promulgam ordens ou leis, escrevem (ou mandam escrever) [...] e vários outros discursos nos meios de comunicação de massa" (VAN DIJK, 2012, p.44)

As escolhas ideológicas são feitas pelos que têm poder. A realização do discurso em instâncias mais restritas já está condicionada às regras estabelecidas antes de sua produção. Portanto, suas escolhas já foram previamente feitas e sobra uma limitada quantidade de opções.

\section{CONSIDERAÇÕES FINAIS}

As construções discursivas indicam que o jornalismo brasileiro da década de 2010, realizado pelo Portal G1, dispõe de outras formas de comprometimento com a informação divulgada, sobre as quais não nos alongaremos neste artigo, mas vislumbramos a possibilidade de um campo profícuo de estudos sobre a mídia hegemônica. 
Relembremos que, nas palavras de Charaudeau (2009, p.19): “A informação é essencialmente uma questão de linguagem, e a linguagem não é transparente ao mundo, ela apresenta sua opacidade através da qual se constrói uma visão de mundo [...]" e essas construções opacas podem causar efeitos "perversos" ou construir notícias falsas.

As recontextualizações, amparadas pelo discurso didático da mídia, criam uma áurea de veracidade e de segurança. Quem entende esse discurso abre a possibilidade de engajar-se num jogo de comprometimento de construção coletiva da narrativa, sentindo-se coautor ou coautora. É dado ao/à leitor/a o poder de narrar a outrem, discutir, como fatos triviais, cada uma das 50 fases da Lava Jato, tratando como verdades consolidadas (como tramitado e julgado) o que ainda são delações.

Esse movimento que o leitor realiza ao relacionar matérias postadas em diferentes lugares (e no G1 organizadas em páginas em que as interligam) colabora para a construção de narrativas de cada um dos temas pautados e, consequentemente, colabora com o engajamento do/a leitor/a e a sua possível "co-narratividade". Nos anos de 2018 e 2019, percebemos que essa estratégia de vinculação foi utilizada de maneira oposta - criando uma cortina de fumaça pela desconexão de dados -, quando observamos a comunicação durante a campanha e a posse do candidato Jair Bolsonaro, momento em que houve o uso de uma avalanche de "fake news", com grande diversidade de temas. Sugerimos que novos estudos sejam realizados sobre essa questão.

\section{Referências Bibliográficas}

ALDÉ, Alessandra; XAVIER, Gabriela; BARRETOS, Diego; CHAGAS; Viktor. Critérios jornalísticos de noticiabilidade: discurso ético e rotina produtiva. Revista Alceu. v.5 - n.10 - p. 186 a 200 - jan./jun. 2005. p. 186 - 200. Disponível em: http://revistaalceu.com.pucrio.br/media/alceu_n10_alde.pdf. Acesso em: 01 jun. 2017.

AMORIM, Felipe. MACHADO, Rodolfo. Golpe de 64: 'Marcha da Família com Deus pela Liberdade' completa 50 anos; saiba quem a financiou e dirigiu. Ópera Mundi Última Instância | São Paulo - 21/03/2014 - 06h00. Disponível em:

http://operamundi.uol.com.br/conteudo/reportagens/34445/golpe+de+64+marcha+da+familia+com + deus+pela+liberdade+completa $+50+$ anos + saiba+quem+a+financiou+e+dirigiu.shtml . Acesso em 29 jun. 2017.

CASTILHO, Carlos. Apertem os cintos: estamos entrando na era da pós-verdade. 28/09/2016 na edição 921. Observatório da Imprensa. Disponível em:

http://observatoriodaimprensa.com.br/imprensa-em-questao/apertem-os-cintos-estamos-entrandona-era-da-pos-verdade/ . Acesso em: 2 jul. 2017.

CHARAUDEAU, Patrick. O discurso das mídias. São Paulo: Contexto, 2009.

CHOULIARAKI, Lilie; FAIRCLOUGH, Norman. Discourse in late modernity: rethinking Critical Discourse Analysis . Edinburgh University Press:, 1999. 
ESQUIVEL, Adolfo Perez. Golpe no Brasil é parte de um projeto de recolonização da América Latina. In: PRONER, Carol et al. A resistência internacional ao Golpe. Bauru, SP: Canal 6 Editora, 2016, p. s/p.

FAIRCLOUGH, Norman. Discurso e mudança social. Coord. trad., revisão e prefácio Izabel Magalhães. Brasília: Editora Universidade de Brasília, 2001 [1992].

FAIRCLOUGH, Norman. Analysing discourse: textual analysis for social research. Nova York: Routledge, 2003.

LÖWY, Michel. Da tragédia à farsa: o golpe de 2016 no Brasil. In: JINKINGS, Ivana; DORIA, Kim; CLETO, Murilo. Por que gritamos golpe? Para entender o impeachement e a crise política. São Paulo: Boitempo, 2016.

MAINGUENEAU, Dominique. Análise de textos de comunicação. São Paulo: Cortez, 2013.

MAINGUENEAU, Dominique. Pragmática para o discurso literário. São Paulo: Martins Fontes, 1996.

MAGALHÃES, Izabel. Recontextualizações no discurso da Estratégia de Saúde da Família. Cadernos de Linguagem e Sociedade, v. 16, n. 2, 2015.

OLIVEIRA, Ana Cláudia Rodrigues; NEVES JÚNIOR, José Wilson Assis; LANZA, Fábio. Reedição da "Marcha da família, com Deus pela liberdade" 50 anos depois do golpe de 1964: manifestações anacrônicas em favor da Ditadura Militar no Brasil. XXV Semana de Ciências Sociais. 50 anos do Golpe Militar. 8 a 10 de abril de 2014. Universidade de Londrina. Disponível em: http://www.uel.br/eventos/semanacsoc/pages/arquivos/GT2-

\%202014/GT2_Ana\%20Claudia\%20Rodrigues\%20de\%20Oliveira.pdf . Acesso em: 29 jun. 2017.

PINHO, Márcio; SANTIAGO, Tatiana. Nova versão da Marcha da Família percorre ruas do Centro de SP. G1 São Paulo. 22/03/2014 15h45 - Atualizado em 22/03/2014 20h44. Disponível em: http://g1.globo.com/sao-paulo/noticia/2014/03/manifestantes-se-reunem-para-nova-versao-damarcha-da-familia-em-sp.html . Acesso em: 29 jun. 2017.

RAMONET, Ignacio. Meios de comunicação: um poder a serviço de interesses privados? In: MORAES, Dênis; RAMONET, Ignacio; SERRANO, Pascual. Mídia, poder e contrapoder: da concentração monopólica à democratização da informação. São Paulo: Boitempo, 2013.

SEABRA, Roberto. Jornalismo político: história e processo. In: SEABRA, Roberto; SOUSA, Vivaldo de (org.). Jornalismo Político: Teoria, história e técnicas. Rio de Janeiro: Editora Record, 2006.

VAN DIJK, Teun. Discurso e poder. São Paulo: Contexto, 2010. 